Thorax (1962), 1', 61.

\title{
BRONCHIAL ADENOMA
}

\author{
BY \\ S. ZELLOS* \\ From the Department of Clinical Surgery, University of Edinburgh
}

(RECEIVED FOR PUBLICATION FEBRUARY 13, 1961)

During the past 12 years, 40 patients investigated in the Regional Thoracic Unit in Edinburgh because of respiratory symptoms have been shown to have as the cause of these symptoms a tumour known as "bronchial adenoma." During the same period 3,000 patients with bronchial carcinoma have been investigated in the same unit. The 40 cases of bronchial adenoma are presented with the object of demonstrating that this tumour is malignant and differs in only three significant ways from bronchial carcinoma: adenomas grow slowly, they occur more frequently in women, and when they metastasize long survival in the presence of metastases is common.

\section{MATERIAL}

The age and sex of the 40 patients with bronchial adenoma are given in Table $I$ and the other relevant

TABLE I

INCIDENCE OF AGE AND SEX

\begin{tabular}{l|c|c|c|c|c|c}
\hline Age (yr.) & $10-20$ & $21-30$ & $31-40$ & $41-50$ & $51-60$ & $61-70$ \\
\hline $\begin{array}{l}\text { Females } \\
\text { Males }\end{array}$ & 0 & 3 & 1 & 4 & 9 & 6 \\
\hline Total & 1 & 3 & 2 & 2 & 5 & 4 \\
\hline
\end{tabular}

details in Table II. The reasons which led these patients to submit to investigation fall into four categories. Twelve patients presented because of haemoptysis ; in eight of these. on close questioning a previous history of some respiratory trouble was obtained, extending in one case over 12 years. Seven patients presented because of an abnormality found on routine mass radiography. and in four of these it was possible to obtain a story of mild chronic respiratory symptoms, in one for nine years. Sixteen patients presented with chronic respiratory symptoms, and haemoptysis was a symptom in eight cf them; in six of these the reason for attending hospital was a recent exacerbation of symptoms associated in one

* Present address : Regional Thoracic Surgical Centre, Shotley Bridge General Hospital, Newcastle upon Tyne. with a hydropneumothorax (Fig. 1). Five patients presented with recent acute respiratory symptoms, one having an empyema, but none gave a history of chronic respiratory disturbance.

The radiographic changes produced by the bronchial adenoma in these $\mathbf{4 0}$ patients fell into two groups. Twenty-five patients presented with the radiographic changes of pulmonary shrinkage; in seven of these the atelectasis was segmental, in 17 lobar, and in one pulmonary. One patient with a middle lobe opacity and wheeze was found to have an adenoma in the trachea and the shrinkage of the middle lobe was the result of aspiration. Fourteen patients presented with a peripheral spherical type of pulmonary opacity; in three of these the opacity lay close to the pulmonary hilum and these three had, in addition, a segmental opacity.

All 40 patients were examined with the bronchoscope. In 29 a tumour was visible in one of the major bronchi or in the trachea (one patient). In 11 the bronchi were endoscopically normal. These 11 patients had peripheral spherical pulmonary opacities without an additional segmental opacity. The patient in whom an adenoma was found in the trachea had a normal middle orifice. In the 29 patients in whom an abnormality was seen bronchoscopically, a biopsy was made from the tumour; in seven of these the histological appearance was interpreted as showing the "changes of carcinoma"; in 22 the biopsy material was recorded as showing the changes of bronchial adenoma. Other investigations in the patients with only peripheral opacities were unhelpful.

Of the 40 patients, 38 were submitted to thoracotomy and two were not. One of these two patients (Case 40) presented with a thyroid swelling and a peripheral pulmonary opacity. It was thought that she might have a thyroid carcinoma with pulmonary metastases. A decision had not been reached regarding treatment when she died from pulmonary embolism. The thyroid lesion was a benign goitre and the peripheral pulmonary lesion was a carcinoid type of bronchial adenoma. The second patient not submitted to thoracotomy (Case 39) was a woman of 40 years who presented with acute respiratory symptoms; she had both an empyema and middle and lower lobar atelectasis. The empyema was drained 
TABLE II

40 PATIENTS WITH BRONCHIAL ADENOMA

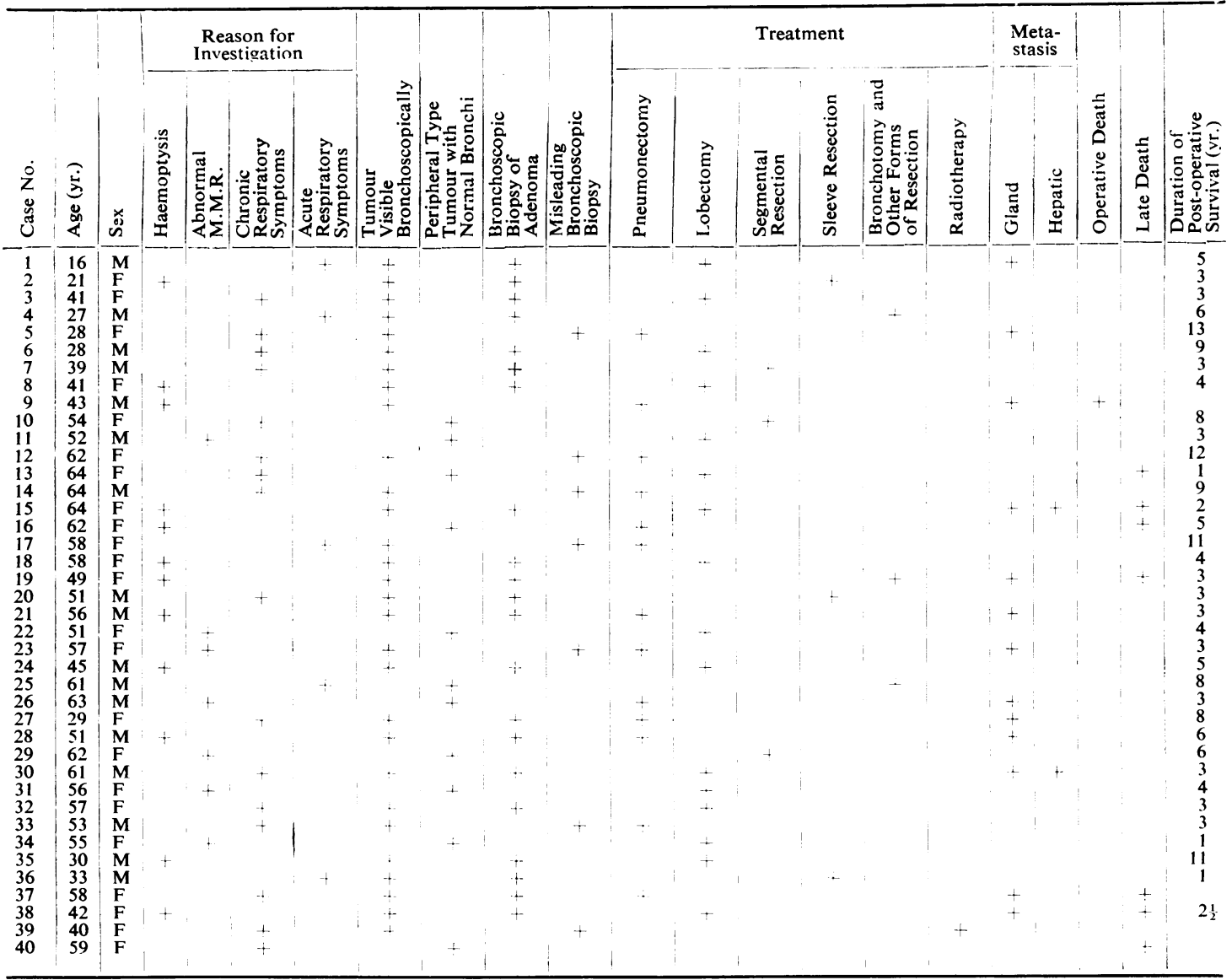

by rib resection. Bronchoscopically, the tumour in the intermediate bronchus had the macroscopic appearances of an adenoma but the histological findings were of bronchial carcinoma. The patient declined thoracotomy and the tumour was irradiated. The empyema continued to discharge for several years. The biopsy material was then reviewed and the appearances were recognized as those of bronchial adenoma. The patient is well 14 years after rib resection and $13 \frac{1}{2}$ years after radiotherapy. She still has a discharging empyema and declines further treatment.

Resection was undertaken in 38 patients, in ten because of a peripheral spherical pulmonary opacity with an incomplete diagnosis, in 22 with the histologically established diagnosis of bronchial adenoma. and in six with the histological diagnosis of bronchial carcinoma, although in all these six the macroscopic appearances at endoscopy were more suggestive of bronchial adenoma. In those patients submitted to thoracotomy the adenoma was in the trachea in one, in the left lung in 13, and in the right lung in 24 .
The patient with the tracheal tumour (Case 19) was submitted to local excision of the tumour and the tracheal defect was repaired with tantalum mesh supported by pericardium. Pneumonectomy was undertaken in 13 patients, seven on the left side and six on the right. Middle and lower lobectomy on the right was undertaken in four patients. In 12 patients a single lobe was resected: right upper lobe (1), left upper lobe (1), middle lobe (4), right lower lobe (5), and left lower lobe (1). From three patients a single segment was resected, the lingula, the apical segment of the right lower lobe, and the anterior basal segment of the right lower lobe. In three patients, lobectomy of the left upper lobe, the right upper lobe, and the left lower lobe respectively was combined with sleeve resection of the stem bronchus. In one patient submitted to left thoracotomy the left stem bronchus was opened and the tumour and its pedicle were excised and the bronchus was then closed (Case 4, Fig. 1). In the last patient a mass $3 \mathrm{~cm}$. in diameter was enucleated from the right upper lobe without any resection of pulmonary tissue. 


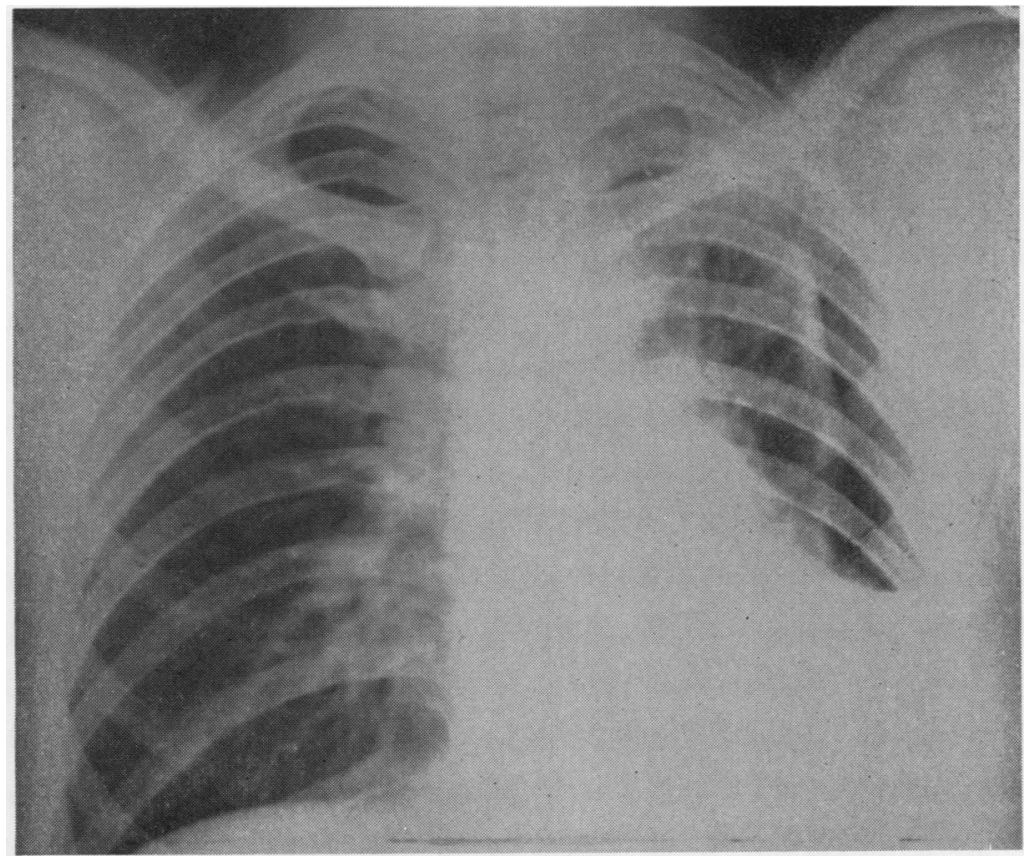

FIG. 1.-Case 4. Postero-anterior view of chest showing a left hydropneumothorax in a patient found to have a bronchial adenoma in the left main bronchus.

It may seem extravagant to have undertaken pneumonectomy in 13 patients. Six were patients in whom the biopsy material had been interpreted histologically as showing the changes of bronchial carcinoma, and all these patients were operated on at a time when pneumonectomy was regarded as the only acceptable resection for bronchial carcinoma. In two of the remaining seven patients, the lung on the side of the bronchial adenoma was shrunken and largely destroyed so that there was no indication for a more conservative resection (Fig. 2). In the remaining five patients pneumonectomy was undertaken because any smaller resection was technically impossible.

In 13 patients in whom resection was undertaken, regional lymph glands showed invasion by tumour cells. In two of these, both submitted to right thoracotomy, the upper surface of the liver was felt through the diaphragm to contain nodules. The diaphragm was opened and tissue was taken from one of many hepatic metastases. The histological interpretation of these metastases was that of bronchial adenoma. In both these patients lobectomy was undertaken as a palliative procedure because they were greatly disturbed by haemoptysis.

One patient died on the tenth post-operative day from pulmonary embolism as a direct consequence of operation (Case 9). The patient with the tracheal adenoma died three years after local excision of the tumour from asphyxia consequent upon a tracheal recurrence. One of the patients known to have hepatic metastasis at the time of resection died two years later (Case 15, Fig. 3). She did not die in hospital, but her general practitioner states that she had manifestations of wide dissemination of tumour. A woman who had no glandular metastases at the time of operation (Case 13) died a year later with metastases in the cerebellum and in the left suprarenal. Another woman (Case 38) died two years after lobectomy with nodular hepatomegaly and scalp metastases. Two patients died from non-metastatic causes, one (Case 37) six months after pneumonectomy with a contralateral pneumonia and the other (Case 16) five years after pneumonectomy, the result of a cerebral vascular accident; neither had glandular metastases at operation. Ten of the patients at present alive had glandular metastases at the time of operation, and one of these, alive three years after resection, had hepatic metastases (Case 30). This patient now has some of the manifestations of the carcinoid syndrome. All the patients at present alive, who were shown at the time of operation to have glandular metastases, have lived for more than three years at the time of writing, and one has lived for 13 years post-operatively.

Of the 40 bronchial adenomas, 33 were of the carcinoid type, six were of the cylindroid type, and one showed features of both varieties of tumour. Hilar glandular metastases were found in two of the six patients with a cylindroid type and in ten of the patients with the carcinoid type of adenoma. Both the patients with hepatic metastasis 


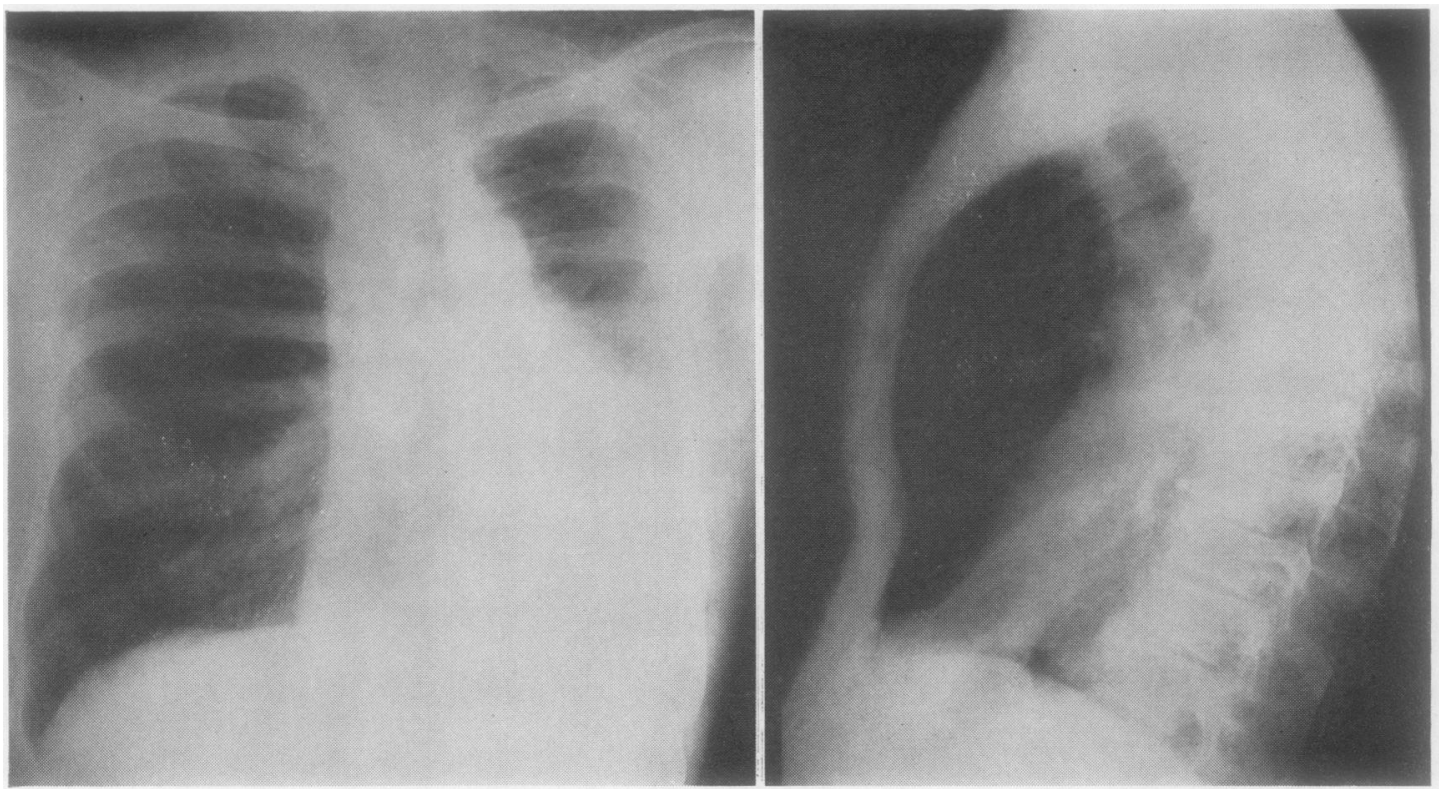

FIG. 2.-Postero-anterior view of chest showing shrunken left lung, the consequence of obstruction of left main bronchus by an adenoma. Aerated pulmonary tissue to left of mediastinum is right lung which has herniated across mediastinum; postoperative film made after left pneumonectomy differed in no significant way from pre-operative films.

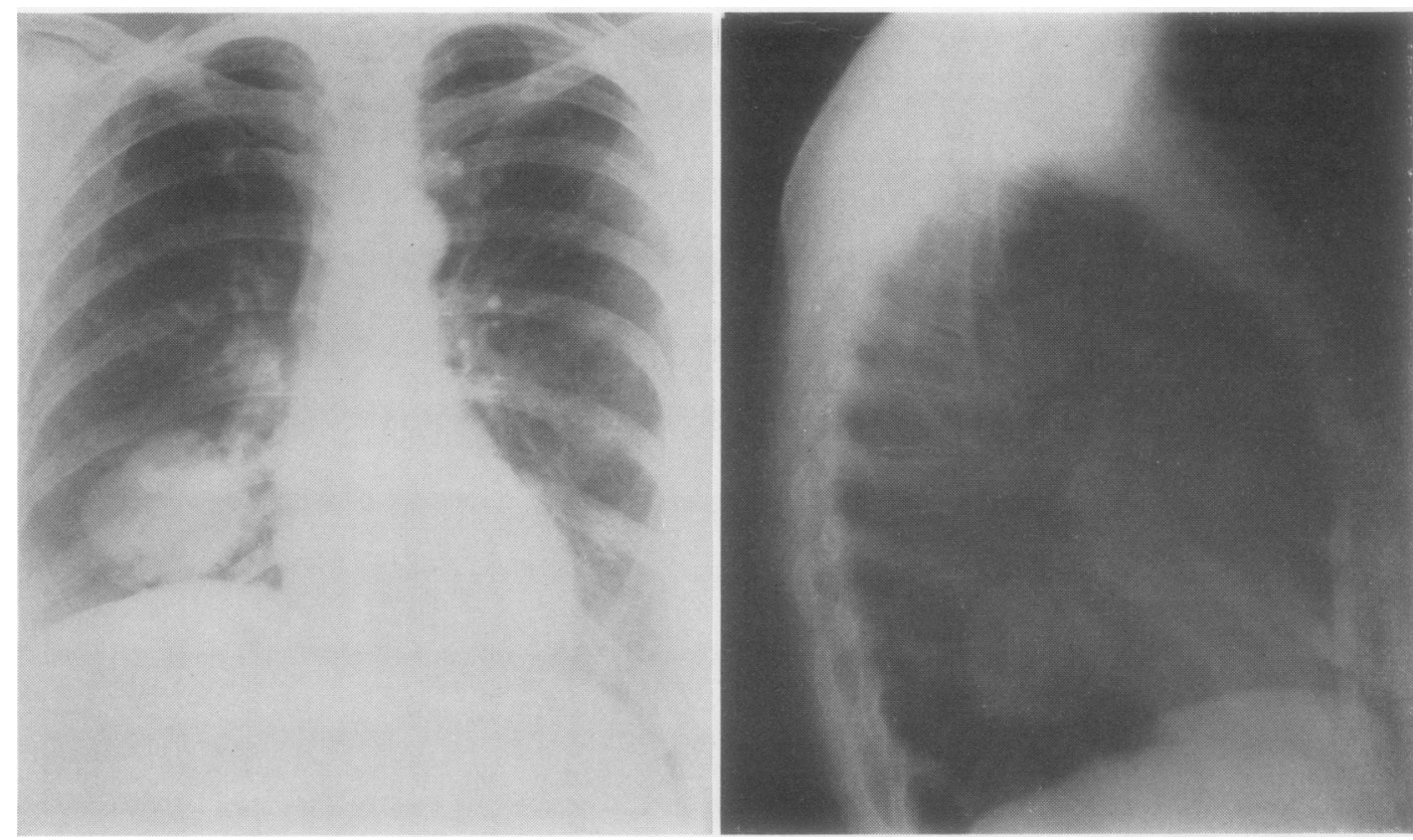

Fig. 3.-Case 15. Postero-anterior view of chest showing an adenoma in periphery of right lower lobe in a patient found at operation to have hepatic metastasis. 


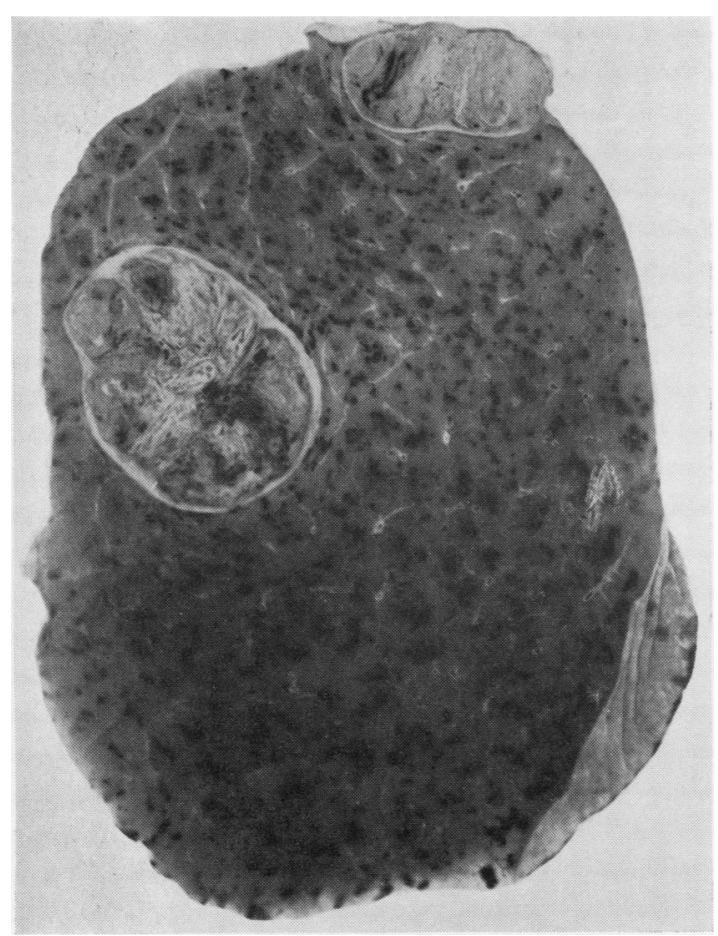

FIG. 4.-Case 11. Right upper lobe showing two separate tumours which histologically were cylindroid in type.

had carcinoid tumours, and one of these now has the manifestations of the carcinoid syndrome. One patient submitted to right upper lobectomy (Case 11) had. radiographically and at thoracotomy, two separate lumps in the right upper lobe (Fig. 4); both were adenomas of the cylindroid type. The patient was an arc welder, and in the right upper lobe were the histological features of arc welder's lung.

Middle lobectomy was undertaken in four patients and middle and lower lobectomy in four. but the latter had tumours growing predominantly in the middle lobe. The incidence of bronchial adenoma in the middle lobe appears disproportionately high compared with other parts of the lung. In comparison with other series the incidence of peripheral tumours is high in relation to the number of bronchoscopically visible tumours.

\section{Discussion}

Bronchial adenoma was first recognized at necropsy in 1882 (Müller). Similar cases were reported by Heine (1927) and Reisner (1928). The lesion was first diagnosed clinically in 1930 by Kramer, who recognized that the tumour might undergo malignant change and that the patient might give a long history; this fact he correlated with the slow growth of the tumour. Clerf and Crawford (1936) described the tumour as benign and arising from the mucous glands of the bronchus. Hamperl (1937) distinguished two varieties of bronchial adenoma, the cylindroid and the carcinoid types. He maintained that the carcinoid variety of bronchial adenoma, unlike the carcinoid tumour of the appendix vermiformis, did not contain argentaffin cells. Recent works have shown this observation to be invalid (Holley, 1946 ; Feyrter, 1959; Williams and Azzopardi, 1960). The present view is that the carcinoid variety of bronchial adenoma is a carcinoid tumour arising in the bronchus, little different from carcinoid tumours elsewhere and capable of giving rise to the carcinoid syndrome. The varieties of the carcinoid syndrome have been well summarized by Davies (1960). The cylindromatous variety of bronchial adenoma is said to resemble basal cell carcinoma of the skin. Regarding the pathogenesis of bronchial adenoma, Reisner (1928) and Kramer (1930) believed the tumours to arise from duct epithelium of the bronchial glands. Churchill (1937) and Womack and Graham (1938) thought they arose from residual embryonic pulmonary tissue consisting of endodermal and mesodermal elements, resembling in this respect mixed salivary tumours; they carried the comparison further, suggesting that bronchial adenoma should therefore be a malignant tumour. Willis (1953) believed that the tumours arose from the mucous and mixed glands of the bronchial wall and again compared them with mixed salivary tumours. Felton, Liebow, and Lindskog (1953) believed that the peripheral type of bronchial adenoma had a different origin from the central variety, and they suggested that the peripheral tumours arose from the lining epithelium.

Rogers (1955) has been able to produce bronchial adenomas in mice by applying nitrogen mustard to the bronchial mucosa. No other carcinogenic agent has been found to produce bronchial adenoma experimentally, and the carcinogenic influences of tobacco smoke have not been inculpated in the pathogenesis of this tumour. The higher incidence amongst women suggests that the aetiological factors leading to bronchial carcinoma do not produce bronchial adenoma.

The incidence of bronchial adenoma in relation to other pulmonary tumours is reported variously by different authors. In the present series 40 bronchial adenomas were identified in a 12-year period during which 3,000 bronchial carcinomas were seen, an incidence of bronchial adenoma of $1.3 \%$. Naclerio and Langer (1948) found that bronchial adenomas accounted for $8 \%$ of all 


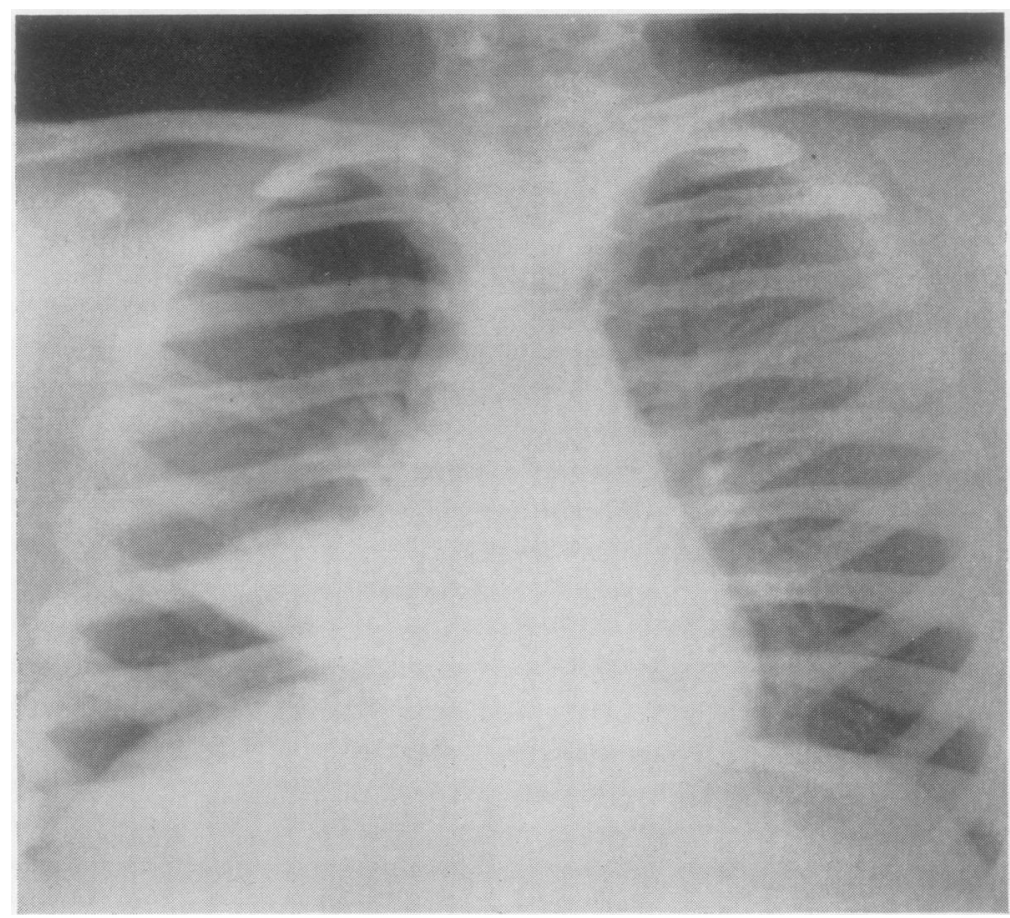

FIG. 5.-Case 1. Postero-anterior view from boy then 8 years; taken in 1947.

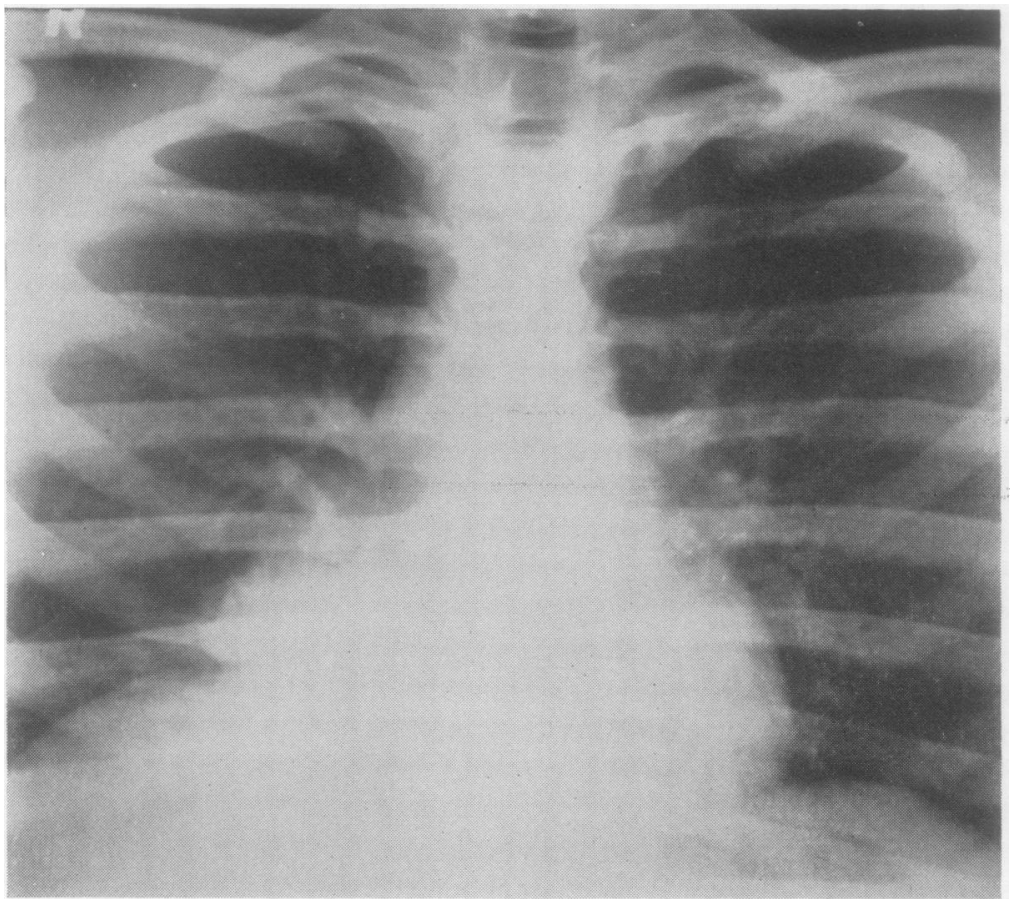

FIG. 6.-Case 1. Postero-anterior view taken in 1955 when resection was undertaken. Glands were invaded by tumour. 
tumours of the lower respiratory tract. Souders and Kingsley (1948) reduced this incidence to $6.9 \%$, Willis (1953) to $5 \%$, and Price Thomas (1954) to $2 \%$. During a mass radiography campaign in Edinburgh in 1948, 300,000 patients were radiographed. Seventy-one patients with bronchial carcinoma were found during this campaign and two patients were found to have an adenoma of the bronchus.

While all authors report a higher incidence amongst women than men, the ratio of women to men varies considerably. Price Thomas (1954), reviewing the literature, stated that the ratio of men to women was one to four, whereas in his own series of 41 patients the ratio of men to women was similar to that reported in the present series.

Foster-Carter (1941) found the highest incidence of bronchial adenoma in the 31-40 age group. Half of the patients in the present series were over the age of 50 . Moersch and McDonald (1950) found the average age amongst women to be 38 years and amongst men 42 years. Their youngest reported patient was 15 years. The youngest patient in the present series (Case 1) was 16 years, and this boy had had symptoms for eight years before he was seen (Figs. 5 and 6). In the present series the average age at onset of symptoms was 43 years and the average duration of symptoms before the patient presented for investigation in hospital was five and a half years.

The commonest presenting symptom of bronchial adenoma is haemoptysis. Foster-Carter (1941) found that $81 \%$ of his series of bronchial adenomas had caused haemoptysis and Price Thomas (1954) found that $53 \%$ of his patients presented because of haemoptysis. In the present series $30 \%$ presented with haemoptysis and an additional $20 \%$ had had haemoptysis. Cough is a common symptom and dyspnoea less common. The usual variety of dyspnoea is a result of bronchial obstruction; patients frequently wheeze and can often localize the position of the tumour by the position of the wheeze. The presence of a tumour in the bronchus may also produce generalized bronchospasm.

The other common symptoms are those resulting from bronchial obstruction with distal infection. Probably because of the long duration of the tumour the lung subtended by a bronchus obstructed by tumour is usually severely damaged (McBurney, Clagett, and McDonald, 1952). The peripheral type of tumour is most frequently found in symptomless patients on routine radiography. Clubbing of the fingers is a less common feature of bronchial adenoma than of bronchial carcinoma. In the present series of 40 patients only four had abnormal fingers.

The position of the tumour in the bronchus and lung involved has been remarkably consistent from one series to another. The right lung is affected twice as often as the left and the most common site is the right lower lobe. Peripheral tumours occur in any part of either lung, and there are several reports of multiple peripheral tumours (Brock, 1938 ; Liebow, 1952 ; Felton et al., 1953). One patient in the present series had two peripheral cylindromatous adenomas. The incidence of peripheral tumours in this series is higher than in previously reported series.

The endoscopic appearance in those patients with central tumours is usually characteristic, and it is common for the experienced endoscopist to recognize that the tumour in the bronchus is at least different from bronchial carcinoma, and probably a bronchial adenoma. The endoscopically visible tumour is sometimes pedunculated with a recognizable stalk, but more frequently only part of the tumour projects into the bronchus and the part within the lung is usually considerably larger than that visible in the bronchus. The cylindromatous variety of tumour is said to have a smoother surface and a paler colour and to bleed less easily than the carcinoid tumour (Overholt, Bougas, and Morse, 1957).

The histological features of both the carcinoid and the cylindromatous varieties of the tumour have been well reviewed (Hamperl, 1937; Moersch, Tinney, and McDonald, 1945 ; Holley, 1946 ; Liebow, 1952 ; Barrett and Thomlinson, 1952 ; Carlens, Wiklund, and Bergstrand, 1954 ; Evans, 1956 ; and Fraser, 1957). The carcinoid type of tumour is much more common than the cylindromatous variety.

The possibility of encountering this tumour must be kept in mind. A long history of respiratory symptoms and particularly a long history of haemoptysis in a patient with a recognizable pulmonary opacity, either peripheral and spherical, or segmental or lobar; a patient younger than those in whom bronchial carcinoma is commonly found; and particularly a female patient, make the diagnosis of the tumour more likely. The endoscopic appearances and the histological interpretation of a biopsy made at endoscopy should establish the diagnosis.

The preferred treatment for bronchial adenoma is resection. Endoscopic resection is inadequate as a curative procedure, and should be reserved for the patient in danger of asphyxiation from 
tracheal obstruction. Segmental resection for a tumour which is potentially malignant is probably not advisable, and lobectomy is probably the smallest resection which is compatible with extirpation of the tumour, and is, in any event, often dictated by the pulmonary changes distal to the tumour. Regional glands should, in all instances, be removed with the resected lobe. Since the tumour is of "low-grade" malignancy, this is the tumour most suitable for lobectomy with "sleeve" resection of the stem bronchus. This operation was pioneered by Price Thomas (1954) im 1946, and D'Abreu and MacHale (1952) reported a case managed in this way. The results of radiotherapy in bronchial adenoma are discouraging. Vieta and Maier (1957) reported 31 cases of cylindromatous adenoma treated by radiotherapy; six of these patients survived more than five years without a recurrence of tumour, but the remainder died after periods varying from four months to four years. One patient in the present series was irradiated more than 13 years ago and she remains well. She will not at the present time submit even to endoscopic inspection of the tumour, so that its change as a consequence of irradiation cannot be assessed.

\section{SUMMARY}

Forty previously unreported cases of bronchial adenoma are recorded. In 33 of these cases the tumours were of the carcinoid variety, and one of these patients now shows the carcinoid syndrome. Six were cylindromatous tumours and one of these was in the trachea. One tumour was of mixed variety. Thirteen patients had lymph gland metastases and two of these had in addition hepatic metastases. Thirty-eight of the 40 patients were submitted to resection and 32 are alive at the present time, 30 of them more than three years after resection and one 13 years after resection.

Bronchial adenoma is a malignant tumour which invades and metastasizes to both lymphatic glands and distant organs. This tumour does not appear to be radiosensitive, and the treatment preferreri at the present time is resection. Lobectomy is probably the smallest resection permissible if an adequate tumour operation is to be undertaken.

I am particularly indebted to Mr. Andrew Logan, at whose suggestion this work was undertaken. for his constant advice and encouragement and for permission to operate on some of his cases. I am also indebted to Dr. J. M. Drennan. of the Pathology Department. University of Edinburgh. for his help.

\section{REFERENCES}

Barratt, N. R. and Thonlinson, R. H. (1952). St. Thomas' Hosp. Rep., 8,5

Brock, R. C. (1938). Lancet, 2, 1041

Carlens, E., Wiklund, T., and Bergstrand, A. (1954). Acta chir. scancl., Suppl. 185.

Churchill, E. D. (1937). J. thorac. Surg., 6. 335.

Clerf, L. H., and Crawford, B. L. (1936). Trans. Coll. Phycns., Philad., 4 ser., 4, 6.

D'Abreu, A. L., and MacHale, S. J. (1952). Brit. J. Surg., 39, 355

Davies, A. J. (1960). In B'itish Surgical Piactice, Surgical Progress, p. 78 . Butterworth, London.

Evans, R. W. (1956). Histological Appearances of Tumours. Livingstone, Edinburgh.

Felton, W. L., Liebow, A. A.., and Lindskog, G. E. (1953). Cancer, 6, 555 .

Feyrter, F. (1959). Virchows Arch. path. Anat., 332, 25.

Foster-Carter, A. F. (1941). Brompton Hosp. Rep., 10, 45

Fraser, K. (1957). Brit. J. Surg., 44, 570.

Hamperl, H. (1937). Virchows Arch. path. Anat., 300, 46.

Heine, J. (1927). Dtsch. path. Ges. Verh., 22, 293.

Holley, S. W. (1946). Milit. Surg., 99, 528.

Kramer, R. (1930). Ann. Otol. Rhin. Laryng. (St. Louis), 39, 689.

Liebow, A. A. (1952), Atlas of Tumor Pathology, Sect. V, Fasc. 17 : Tumo's of the Lower Respiratory Tract. Armed Forces Institute of Pathology, Washington, D.C.

McBurney, R. P., Clagett, O. T., and McDonald, J. R. (1952). J. thorac. Surg., 24, 411.

Moersch, H. J., and McDonald, J. R. (1950). J. Amer. med. Ass., $142,299$.

-Tinney, W. S., and McDonald, J. R. (1945). Surg. Gynec. Obstet., 81, 551 .

Müller, H. (1882). Innaug. Diss., Halle.

Naclerio, E. A., and Langer, L. (1948). Amer. J. Surg., 75, 532.

Overholt, R. H., Bougas, J. A., and Morse, D. P. (1957). Amer. Rev. Tuberc., 75, 865.

Reisner, D. (1928). Arch. Surg. (Chicugo), 16, 1201.

Rogers, S. (1955). J. nat. Cancer Inst., 15, 1379.

Souders, C. R., and Kingsler, J. W. (1948). New Engl. J. Med., $239,459$.

Thomas, C. P. (1954). Lancet, $1,1$.

Vieta, J. O., and Maier, H. C. (1957). Dis. Chest, 31, 493.

Williams, E. D., and Azzopardi, J. G. (1960). Thorax, 15, 30.

Willis, R. A. (1953). Pathology' of Tumours, 2nd ed. Butterworth, G London.

Womack, N. A., and Graham, E. A. (1938). Arch. Puth. (Chicugo), 2S, 195 